Max-Planck-Institut für demografische Forschung

Max Planck Institute for Demographic Research

Doberaner Strasse 114 - D-18057 Rostock - GERMANY

Tel +49 (0) 3812081 - 0; Fax +49 (0) 3812081 - 202;

http://www.demogr.mpg.de

MPIDR WORKING PAPER WP 2002-052

DECEMBER 2002

\title{
On the Changing Correlation Between \\ Fertility and Female Employment over Space and Time
}

Henriette Engelhardt (henriette.engelhardt@oeaw.ac.at)

Alexia Prskawetz (fuernkranz@ demogr.mpg.de)

(C) Copyright is held by the authors.

Working papers of the Max Planck Institute for Demographic Research receive only limited review.

Views or opinions expressed in working papers are attributable to the authors and do not necessarily reflect those of the Institute. 


\title{
On the Changing Correlation Between Fertility and Female Employment over Space and Time*
}

\author{
Henriette Engelhardt ${ }^{\dagger} \quad$ Alexia Prskawetz
}

December 10, 2002

\begin{abstract}
Various authors find that in OECD countries the cross-country correlation between the total fertility rate and the female labor force participation rate turned from a negative value before the 1980s to a positive value thereafter. Based on pooled cross-sectional data, Kögel (2002) shows that (a) unmeasured country-specific factors and (b) country-heterogeneity in the magnitude of the negative time-series association accounts for the reversal in the sign of the cross-country correlation coefficient. Our paper aims to identify those variables that may explain country heterogeneity in the negative association between fertility and female labor force participation. The selection of variables is based on existing macro demographic theories. We apply aggregate descriptive representations of the time series and cross-country evolution of fertility, female employment and a set of labor market, educational and demographic variables and indicators of social policy.
\end{abstract}

*We would like to thank Anne Gauthier for providing data series on wages and indicators for social policies and Dorothea Rieck for assistance with all the data. The view expressed in this paper are the authors' own views and do not necessarily represent those of the Max Planck Institute for Demographic Research and the Institute for Demography of the Austrian Academy of Sciences. For language editing, we would like to thank Jenae Tharaldson and Susann Backer.

${ }^{\dagger}$ Institute for Demography, Austrian Academy of Sciences, Vienna, Austria. Email: Henriette.Engelhardt@oeaw.ac.at.

${ }_{\ddagger}^{\ddagger}$ Max Planck Institute for Demographic Research, Rostock, Germany. Email: fuernkranz@demogr.mpg.de 


\section{Introduction}

Various authors (Ahn and Mira 2002; Brewster and Rindfuss 2000; EspingAndersen 1999; Rindfuss et al. 2000) find that in OECD countries the crosscountry correlation between the total fertility rate (TFR) and the female labor market participation rate (FLP) turned from a negative value before the 1980s to a positive value thereafter. The countries that now have the lowest levels of fertility are those with relatively low levels of female labor force participation and the countries with higher fertility levels tend to have relatively high female labor force participation rates. Following the graphical presentation in the literature (e.g., Rindfuss et al. 2000), Figure 1 illustrates this change for 21 OECD countries. ${ }^{1}$

The change in the sign of the cross-country correlation between TFR and FLP has often been mistakenly associated with a change in the time series association between TFR and FLP (Benjamin 2001, Brewster and Rinfuss 2000, Esping-Andersen 1999, Rindfuss et al. 2002). Recent studies by Engelhardt et al. (2001) and Kögel (2002) show that neither the causality nor the time series association between TFR and FLP has changed over time. By applying error-correction models to six industrialized countries Engelhardt et al. (2001) find Granger causality in both directions, which is consistent with simultaneous movements of both variables brought about by common exogenous factors. Kögel (2002) not only shows that the time series association between TFR and FLP has not changed, but he also offers two convincing elements that may explain the change in the cross-country correlation. These are (a) the presence of unmeasured country-specific factors and (b) country heterogeneity in the magnitude of the negative time-series association between fertility and female employment. Figure 2 (taken from Kögel 2002) illustrates these points by choosing Italy and Sweden, two countries representative for the development of TFR and FLP in the OECD sample. In both cross sections (1965 and 1995) the FLP was higher in Sweden than in Italy (supporting hypothesis (a)) and the increase in FLP is associated with a much stronger decline of the TFR in Italy than in Sweden, which is evidence for hypothesis (b).

Though these recent studies provide econometric evidence on why the

\footnotetext{
${ }^{1}$ The countries included are Austria, Australia, Belgium, Canada, Denmark, Finland, France, West Germany, Greece, Italy, Ireland, Japan, Luxembourg, Norway, the Netherlands, New Zealand, Portugal, Spain, Sweden, Switzerland, United Kingdom, and the United States.
} 
Figure 1: Cross-country correlation between the total fertility rate and female labor force participation rate, 1960-2000

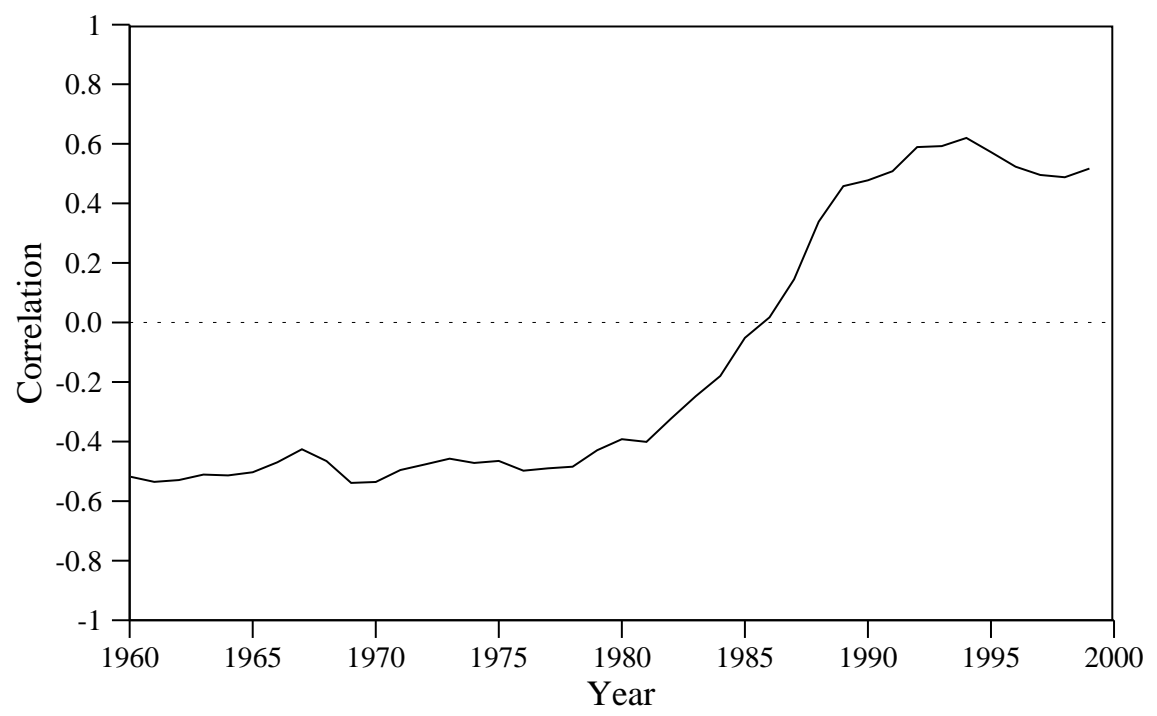

Figure 2: Total fertility rate and female labor force participation rate in Italy and Sweden, 1965 and 1995

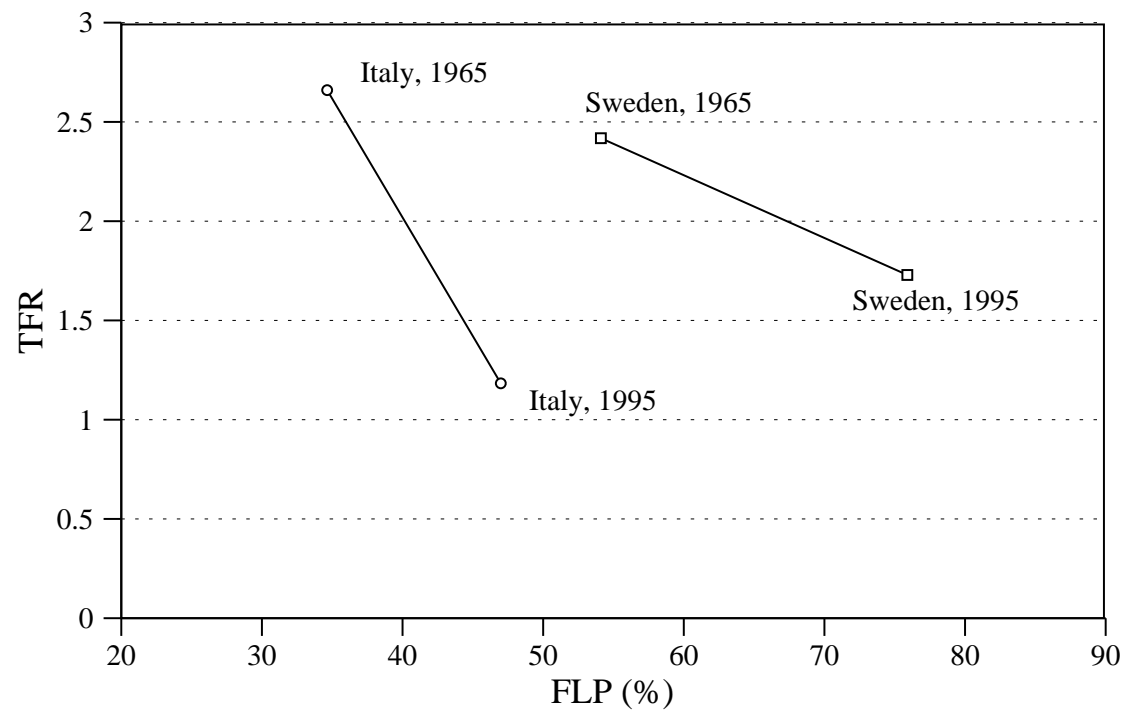


cross-country correlation changed and prove that the time series association has not changed its sign, these studies do not provide us with a possible list of factors that may actually explain the change in the cross-country correlation coefficient. The studies by Ahn and Mira (2002) and Benjamin (2001) offer some theories and data that may explain why the sign of the cross-country correlation between TFR and FLP changed. Ahn and Mira (2002) use an extension of the Butz and Ward (1979) framework to show the importance of income effects of female wages, inflexible working hours, the possibility of purchasing childcare and unemployment. However, only data for aggregate unemployment are actually presented, leaving the rest of the discussion to rest on theoretical considerations. Benjamin (2001) presents an extensive discussion on factors that may cause the reversal of the cross country correlation coefficient but then restricts her analysis to a pooled cross section time series analysis of the TFR in which she only includes male unemployment, GDP and country groups as explanatory variables in addition to FLP.

The aim of our paper is to extend the set of labor market variables and to also include demographic, educational and social policy indicators as plausible factors that may explain the change in the sign of the cross-country correlation coefficient. This inclusion of demographic indicators is warranted by the recent finding of Billari and Kohler (2002) that in European lowest low fertility countries (including Eastern Europe), the cross-country correlation between TFR and traditional determinants of fertility (such as the total first marriage rate and the total divorce rate) has changed its sign as well.

Similar to Ahn and Mira (and suggested by the findings in Kögel 2002) we start off by building country groups that are homogenous with respect to the development of their FLP. While Ahn and Mira base their analysis on three groups of countries that are assembled based on the average level of FLP over the time period 1970-96 (cf. Appendix A) we apply a more dynamic approach and assign countries into three groups based on average levels of FLP over 10-year time periods (1960-1969, 1970-1979, 1980-1989, 1990-1999). We therefore allow countries to belong to different country groups over these four decades. Obviously, our grouping produces more homogenous groups of countries by level of FLP during the 1960s and early 1970s (the time period not considered in the study by Ahn and Mira). In Figure 3 we plot the average level of FLP for the grouping suggested by Ahn and Mira (indicated by the letters A\&M) as well as for our alternative grouping (see Appendix A for details on the country groupings). 
Figure 3: Average level of female labor participation rates in low, medium and high participation countries

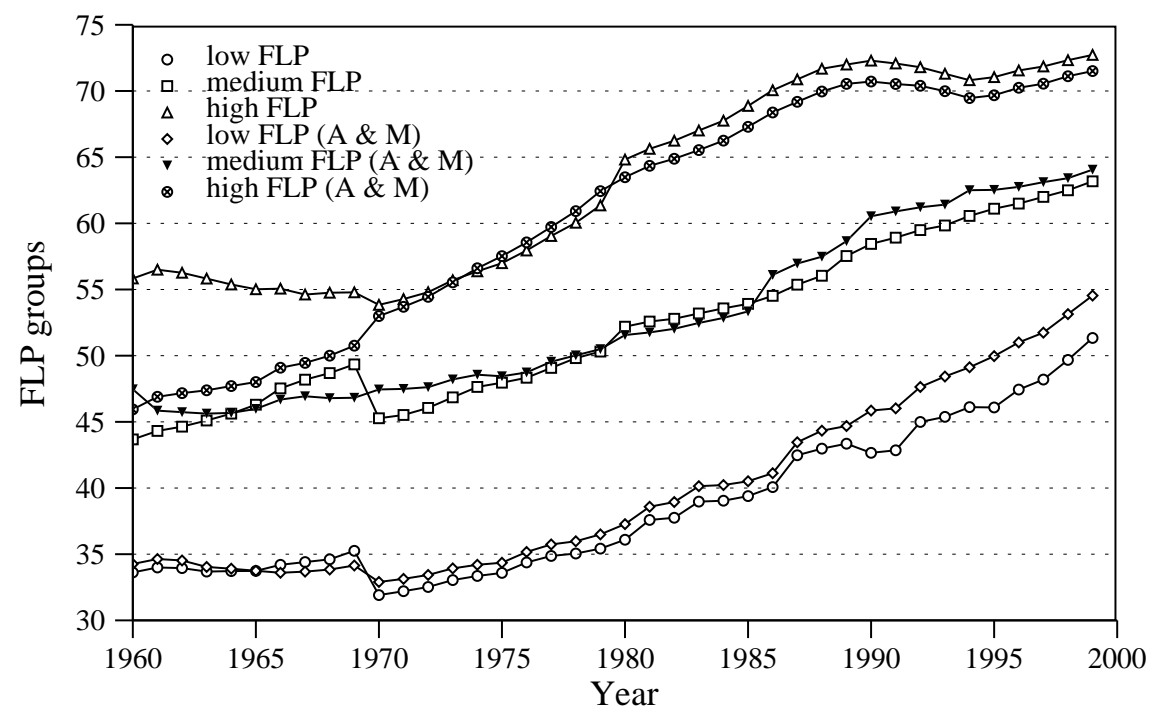

Calculating the average TFR for each country group (Figure 4) (applying our country grouping) confirms the second hypothesis of Kögel (2002): the decline in TFR was much more pronounced in countries with lower FLP levels.

In section four we shall assemble corresponding plots for a set of labor market, educational and demographic variables and indicators of social policy. In particular we are interested in whether the change in the slope of the decline in TFR across low, medium and high participation countries in Figure 4 may be explained by a change in the slope of any of those other factors.

We are aware that our approach is purely descriptive unlike the econometric studies of Engelhardt et al. (2001), Kögel (2002) and Benjamin (2001). This is because several of our proposed indicators are only available for a quinquennial period or less. However, as demonstrated by Ahn and Mira, a fruitful task to start with could be good descriptive illustration of a hypothesis that may have caused the cross-country correlation coefficient to change its sign.

In the following section we briefly discuss two macro-economic approaches 
Figure 4: Average total fertility rates in low, medium and high participation countries

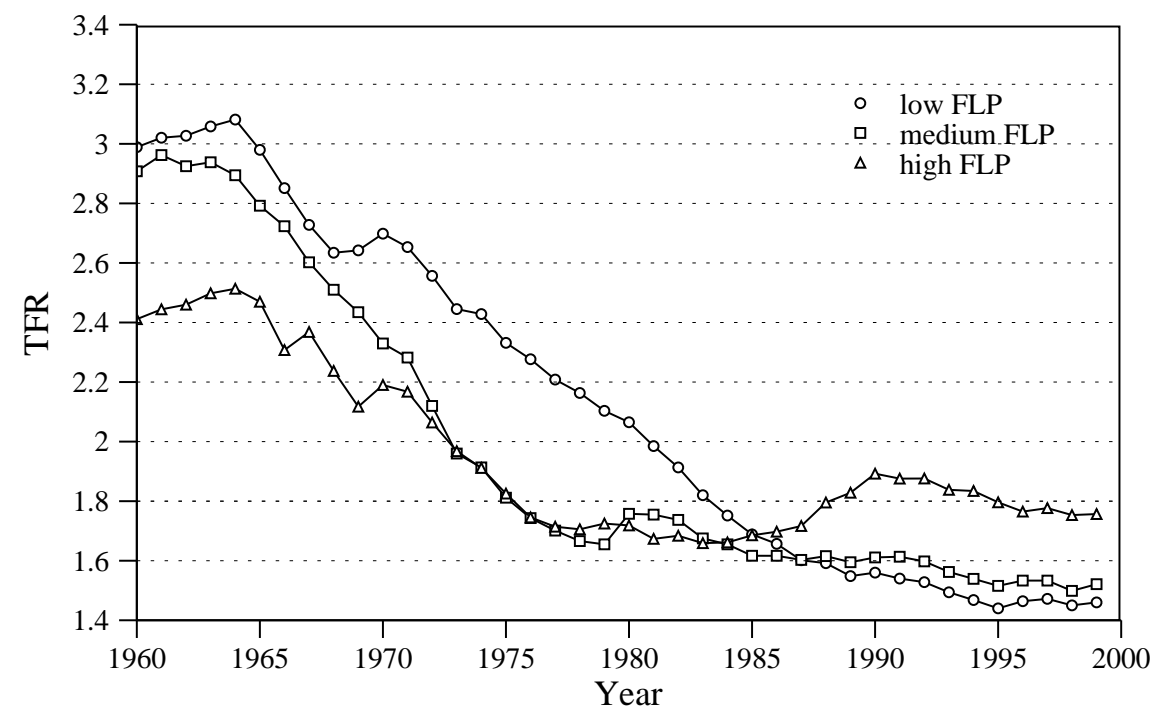

that aim to explain the mutual relationship between fertility and female employment. In section three we shortly describe our variables and the choice of countries. The selection of variables is driven by alternative economic and demographic theories on the relation of fertility and female labor force participation. Section four compiles the descriptive findings. We close with a short discussion and an outlook for future research.

\section{Theoretical Considerations}

In economics, two contrasting schools have emerged to explain the relationship between the changes in fertility and female labor force participation over time: the New Home Economics model and the Easterlin model. Both approaches attempt to put forward explanations for a negative relationship between female employment and fertility. They differ in their identification of the driving force, as indicated by the respective labels used to describe them: the 'value of time' model and the 'relative income' model (Sanderson 1976). The New Home Economics (e.g. the model by Willis 1973 and its application by Butz and Ward 1979) focuses primarily on changes in the 
Table 1: Determinants of FLP and TFR

\begin{tabular}{lcc}
\hline \hline & $\begin{array}{c}\text { Association } \\
\text { with FLP }\end{array}$ & $\begin{array}{c}\text { Association } \\
\text { with TFR }\end{array}$ \\
\hline Labor market variables & $+/-$ & $+/-$ \\
Female wages (FW) & - & + \\
Male wages (MW) & - & + \\
Relative male income & + & - \\
Male-female wage ratio (MW-FW) & - & + \\
Female unemployment rate (FUR) & & - \\
Male unemployment rate (MUR) & & $+/-$ \\
Female hours (FH) & + & + \\
Male labor participation rate (MLP) & & - \\
Proportion females in part time (PART) & + & - \\
\hline Educational variables & + & - \\
Female tertiary gross enrolment ratio (GER) & + & - \\
Average years of school of females (YEARS) & + & - \\
Highest female education: 1st level (LEVEL1) & + & + \\
Highest female education: 2nd level (LEVEL2) & & - \\
Highest female education: post 2nd level (LEVEL3) & + & - \\
\hline Demographic variables & - & + \\
Total divorce rate (TDR) & & + \\
Total female first marriage rate (TFFMR) & & \\
Mean age at 1st birth (MAB1) & + & \\
\hline Social Policies & & \\
Gross enrolment ratio of kids in pre-primary education (PREM) & + \\
Family allowances (FA1, FA2, FA3) & & \\
\hline
\end{tabular}

value of a women's time whereas Easterlin $(1980,1987)$ focuses on changes in relative income due to the demographic cycle (the baby boom and bust). The determinants of fertility and female employment mentioned by the two economic schools and by the role incompatibility approach discussed below are summarized in Table 1.

In the New Home Economics, fertility decisions are a function of individual preferences and the costs of children, given an income constraint (Becker 1991; Cigno 1991; Willis 1973). Since parents receive utility from increased child 'quality' and 'quantity', the cost of children is endogenous in the models. The costs of children include opportunity costs (the earning loss from reduced labor supply), child-care costs (including the availability of child-care) and time costs of raising and educating a child (including the domestic division of labor). Offsetting these costs to some extent are labor earnings adjustments 
by other household members as well as public and employer-provided welfare benefits and taxes. Surveys of empirical studies of the New Home Economics fertility model are provided by Macunovich (1996) and Hotz et al. (1997).

The New Home Economics model stresses the role of female wages, representing the opportunity cost of childbearing, as a determinant of fertility (e.g. Willis 1973). Female wages are seen to have both (positive) income and (negative) substitution/price effects on fertility, with opposite effects on female labor force participation. The income effect refers to the fact that when income increases, the demand for children increases as well, thus resulting in an increase in fertility; the substitution effect implies that when income increases, the opportunity cost for having more children increases, thus leading to a dampening effect on fertility. If all childrearing is done by women, an increase in men's wages will have a pure income effect. The overall effect on fertility of a proportional increase in men's and women's wages is theoretically ambiguous. Empirically, the female wage rate (or other measures of the opportunity costs of females) is more often negatively related to fertility (Becker 1991; for an empirical overview see Hotz et al. 1997). Higher female wages delay the timing of all conceptions and reduce total fertility (Heckman and Walker 1990). Reduced wage differentials between men and women lead women to substitute out of childrearing and into the labor market (Galor and Weil 1996).

The potential earnings of women, and hence the price of raising children, have increased as the educational level of women has risen. Given the division of labor within the family, this increase in the earning capacity of women has had an increasingly greater negative impact upon aggregate fertility (Ermisch 1979). Therefore, we expect a positive association between the tertiary gross enrolment ratio, the average years of schooling, and the highest educational level on employment and a negative effect of these factors on fertility. Furthermore, New Home Economics leads us to expect that women with a high degree of human capital (education and training) will delay the birth of their first child (Hotz et al. 1997).

Unemployment is not explicitly considered in the models of the New Home Economics. However, understood as a zero wage, unemployment induces a strong income effect for households in which the husband is employed, while it should yield both income and substitution effects if a participating wife becomes unemployed (Ahn and Mira 2002). However, empirical evidence shows mixed results: Andersson (2001) reports a stronger income effect for individual female unemployment in Sweden during the 1980s and 1990s, while 
Kravdal (2002) finds a slightly stronger substitution effect for individual unemployment for first births in Norway in the period 1992-98, and a slightly stronger income effect for higher-order birth rates.

Butz and Ward (1979) used the New Home Economics model to define a causal macro level relationship between fertility and female employment. In this model, it is postulated that fluctuations in fertility can be attributed to a dominant substitution effect of a rising female wage, and subsequently varying levels of female labor force participation. Note, however, that participation rates are considered to be exogenous to fertility rates, whereby the participation rate depends on the joint distribution of male and female wages (which are treated as exogenous) and other characteristics.

Easterlin's 'relative income' hypothesis is, like the Butz' and Wards' model, a macro approach to fertility and female employment. The linkage between higher birth rates and adverse economic and social effects arises in Easterlin's approach from 'crowding mechanisms' operating within the family, school, and labor market (Easterlin 1980, 1987). Easterlin emphasizes the role of male incomes, relative to economic aspirations, as the driving force behind fertility and female labor force participation. Economic aspirations of young adults are determined by material conditions prevailing in their parental homes during their teenage years. An increase in income relative to economic aspirations shifts preferences in favor of childbearing and away from female labor force activity and a decrease in relative income results in increased female employment, delayed childbearing and reduced fertility. However, in his first theoretical considerations women were not considered because Easterlin assumed that women are not on the labor market (Easterlin 1978).

In the full Easterlin model relative income is affected by the size of the young cohort relative to that of prime aged adults, both measured contemporaneously. An unusually large cohort of young adults faces competition from their peers in education and employment opportunities, which leads to adverse consequences on their earnings. At the same time the earnings of their parents, who were attached to a smaller birth cohort, may have been unusually high, which would have contributed to the formation of high material aspirations for the subsequent generation as they faced decisions concerning fertility and labor market activity in their early adult years. Thus, the driving force behind both increased female labor force participation and reduced fertility is the desire of a larger birth cohort to improve relative economic status, with parental income as the measure of material aspirations. Empir- 
ical tests of the Easterlin model have been surveyed by Pampel and Peters (1995) and Macunovich (1998). The literature suggests support for the relative income concept in fertility, but it seems to be less clear regarding the sources of differences in material aspirations.

Because both the neoclassical model and the Easterlin story based on wage structures poorly explain either common time trends or cross-national variation in fertility and female employment, the emerging alternative hypothesis in the demography literature is that societal level responses have eased the incompatibility between childrearing and female employment (Brewster and Rindfuss 2000; Rindfuss et al. 2000; Rindfuss and Brewster 1996; Engelhardt et al. 2001). This hypothesis in turn nests within the broader hypothesis that state policies affect fertility rates by changing the costs of children mentioned at the start of this section (see e.g., Gauthier 1996). This alternative approach to the costs of children focuses less narrowly on the female wage as the measure of the 'price' of children. Instead it turns attention to the ability of women to combine childbirth and work, and to the overall costs, both to the household standard of living and to the woman's career, that arise from interruptions or reductions of labor supply in conjunction with childbirth and child-rearing. This approach is qualitatively different from the neoclassical approach in that it focuses attention not on the wage structure of a given society, but rather on the complex of social and economic institutions. These institutions in turn determine how easily a woman can combine work and family, that determine how costly it is to the family when a women reduces her labor earnings, and that determines how large the wage or career opportunity cost is based on the experienced labor market reduction (cf. DiPrete et al. 2002).

The changes in the industrial and occupational structure have expanded employment opportunities for women, especially for part-time employment (O'Reilly and Fagan 1998). Increasing rates of part time employment, however, reduce the opportunity costs of children and, thus, increase fertility.

A measure of the availability of child-care is the gross enrolment ratio of children in pre-primary education. Due to reduced opportunity costs this ratio should have a positive effect on the aggregated fertility rate as well as a positive effect on female employment. Family allowances reduce the income constraint and, therefore, are expected to have a positive effect on fertility.

Though not explicitly included theoretically by either the two schools of economics or by the role incompatibility hypothesis, the effects of other demographic variables (e.g. the total first marriage rate and the total divorce 
rate) on fertility and female employment can easily be derived by some ad hoc considerations guided by a general (family) economic framework. Marriage rates and divorce rates follow economic cycles. Positive economic developments coincide with increasing marriage and divorce rates (Cherlin 1992).

Easterlin (1980: 87) empirically observes, "...that low childbearing makes for high divorce, and vice versa..." . A hypothesis for this phenomenon would be that the perception of increasing divorce rates could be a "self-fulfilling prophecy". Women with doubts about a lifetime relation with their partners may invest less in their relationships with the result of an increased divorce risk due to the minor investments in marriage. The aggregate result of this feedback effect might be a negative relationship between divorce rates and fertility rates and a positive relationship between divorce rates and female labor force participation rates.

Associated with declining fertility rates, especially in Southern Europe, is the emergence of a situation in which long-term partnership commitments - symbolized through legal marriages - are declining (e.g. Billari and Kohler 2002). Withdrawing from a long-term investment in marriage may also coincide with a withdrawal from fertility. Generally it is assumed that there is a positive relationship between marriage rates and fertility rates and a negative relationship between marriage rates and participation rates.

\section{Data and Variables}

To describe the changing correlation between fertility and female employment, we use a set of labor market variables, educational variables, demographic variables and indicators of social policies, as discussed below. The data used in the empirical analysis are compiled from a number of publicly available sources to construct a full series of single-year figures from 1960 to 2000. For an overview of data and sources see Table 2. The countries included are Austria, Australia, Belgium, Canada, Denmark, Finland, France, West Germany, Greece, Italy, Ireland, Japan, Luxembourg, Norway, the Netherlands, New Zealand, Portugal, Spain, Sweden, Switzerland, United Kingdom, and the United States. The selection of countries is based on the availability of data for our indicators.

Our two central variables are TFR and FLP. The TFR is a period fertility rate that takes into consideration the age structure of a population. It is the hypothetical number of children a women would have if she experi- 
Table 2: Variables and Sources

\begin{tabular}{ll}
\hline \hline Variables & Sources \\
\hline Main variables & United Nations Demographic Yearbook, \\
Total fertility rate (TFR) & $\begin{array}{l}\text { New Cronos (Eurostat Database), } \\
\text { German Federal Statistical Office } \\
\text { Comparative Welfare Data Set(b), } \\
\text { OECD Labor Force Statistics }\end{array}$ \\
Female labor participation rate (FLP) & ILO Yearbook of Labour Statistics, \\
\hline Labor market variables & Comparative Family Benefits Database(a) \\
Female wages (FW) & = Female Wages / Male Wages \\
Male wages (MW) & Comparative Welfare Data Set(b), \\
Male-female wage ratio (MW-FW) & OECD Labor Force Statistics \\
Male unemployment rate (MUR) & ILO Yearbook of Labor Statistics \\
Female hours (FH) & Comparative Welfare Data Set(b), \\
Male labor participation rate (MLP) & OECD Labor Force Statistics \\
Proportion females in part time (PART) & OECD Labor Force Statistics
\end{tabular}

Educational variables

Female tertiary gross enrolment ratio (GER) UNESCO(c)

Average years of school of females (YEARS) Barro and Lee (2001),

de la Fuente and Doménech (2002)(d)

Highest female education: 1st level (LEVEL1) Barro and Lee (2001),

de la Fuente and Doménech (2002)(d)

Highest female education: 2nd level (LEVEL2)Barro and Lee (2001),

de la Fuente and Doménech $(2002)(d)$

Highest female education: post 2nd level Barro and Lee (2001),

(LEVEL3) de la Fuente and Doménech $(2002)(\mathrm{d})$

Demographic variables

Total divorce rate (TDR)

Council of Europe (2001)

Total female first marriage rate (TFFMR) Council of Europe (2001)

Mean age at 1st birth (MAB1) New Cronos CD 2001,

Social Policies

Council of Europe (2001)

Gross enrolment ratio of kids in pre- Comparative Family Benefits Database(a)

primary education (PREM)

Family allowances for 1st child (FA1) Comparative Family Benefits Database(a)

Family allowances for 2nd child (FA2) Comparative Family Benefits Database(a)

Family allowances for 3rd child (FA3) Comparative Family Benefits Database(a)

Notes: a) Assembled by Gauthier (2002). b) Assembled by Huber et al. (1997),

http://lisweb.ceps.lu/publications/welfaredata/welfareaccess.htm.

c) http://unescostat.unesco.org/en/stats/stats0.htm.

d) http://www2.cid.harvard.edu/ciddata/barrolee/Appendix.xls. 
enced the age-specific fertility rates of a given time period in her reproductive lifetime. The TFR is compiled from different sources: the United Nations Demographic Yearbook, the New Cronos Eurostat Database, and the German Federal Statistical Office.

The FLP is the number of women working part- or full-time or actively seeking employment at ages 15-64 divided by the total female population aged 15-64. Ideally, one would want the FLP for women of childbearing years only, but age-specific single-year data was not available for all countries. The FLP data from 1960 to 1994 for most of our countries is available online through the Comparative Welfare Data Set, assembled by Huber et al. (1997). For Greece and Spain as well as for the other countries after 1994, we used various issues of the OECD Labor Force Statistics. ${ }^{2}$ For West Germany we applied data from the German Federal Statistical Office based on the Micro census after 1989.

Our labor market indicators include male labor force participation rates, female wages, male wages, the male-female wage gap, the female and male unemployment rate, female and male working hours, and the share of females in part time employment. Male labor force participation rates (MLP) are defined according to the FLP as described above. The data on hourly female wages (FW), hourly male wages (MW), and weekly female working hours $(\mathrm{FH})$ in non-agricultural activities is published in the "Yearbook of Labour Statistics" by the International Labor Office (ILO). ${ }^{3}$ In a limited number of countries (Canada, Italy, and the United States), wages were not available by sex and were estimated by Gauthier and Hatzius (1997) using other national sources. Gauthier provided the data with a preliminary version of the Comparative Family Benefits Database 1970-2000. Because wages from both sources are measured in the respective national currencies we divided

\footnotetext{
${ }^{2}$ Information is collected by the OECD through responses to annual questionnaires sent to each country and through other national and international sources and reports. Because of possible differences in how a country defines "employment", these numbers are not strictly comparable across countries. Since we compare changes in employment rates over time rather than employment rates across countries, this is not expected to be a problem (Benjamin 2001).

${ }^{3}$ The OECD wage and hours data are mostly obtained from payroll data supplied by a sample of establishments. In a few cases, household sample surveys or social insurance statistics provide the data on hours worked. The data from these various sources are not fully comparable in view of differences in scope, coverage and methods of data collection. However, as in the case of employment rates, this is not expected to be a problem, as we are not comparing wages across countries but rather changes over time.
} 
the national wages by the purchasing power parity (PPP) indexes in US \$ (provided by the OCED National Accounts) that estimate the differences in price levels between countries. As a measure of the gender wage gap we use the ratio of female to male wages. The male and female unemployment rate (MUR, FUR) is defined as the number of persons aged 15 to 64 actively seeking employment divided by the respective numbers of persons in the labor force. Data on FUR and MUR for selected countries till 1994 come from the Comparative Welfare Dataset. For the remaining countries and years data come from the OECD Labor Force Statistics. The latter was also our data source for the number of females in part time employment as a share of the female employment (PART).

As educational variables we employ the tertiary gross enrolment ratio (GER), the average years of schooling of females over age 25 (YEARS) and the highest educational level completed by females over age 25 (LEVEL1, LEVEL2, LEVEL3). The GER is defined by the UNESCO as the "total enrolment in a specific level of education, regardless of age, expressed as a percentage of the official school age population corresponding to the same level of education on a given school year." The data on GER is published online by the UNESCO. The highest educational level is defined as the fraction of the population aged 25 and over that has completed primary schooling (LEVEL1), lower and upper secondary schooling (LEVEL2) and two levels of higher education (LEVEL3). The estimated data on schooling and highest educational level is available online and described by Barro and Lee (2001) and de la Fuente and Doménech (2002). Note that data is only available in five years intervals.

As demographic indicators we include the total divorce rate (TDR), the total female first marriage rate (TFFMR), and the mean age at first birth (MAB1) in our analyses. The TFFMR gives the proportion of females who would ever marry for the first time in a hypothetical cohort of persons who at each age $\mathrm{x}$ experienced the relevant age specific first marriage rates applying in a particular year. Similarly the TDR is the proportion of divorced couples in a hypothetical cohort who at each age $\mathrm{x}$ experienced the relevant age specific divorce rate applying in a particular year. The series are obtained from the Council of Europe (2001). The data for MAB1 is from the New Cronos CD 2001.

Finally, as indicators for national social policies we take the gross enrolment ratio in pre-primary education (PREM) and the monthly family allowances for the first, second and third child in national currency (FA1, 
Figure 5: Average male labor participation rates in low, medium and high participation countries

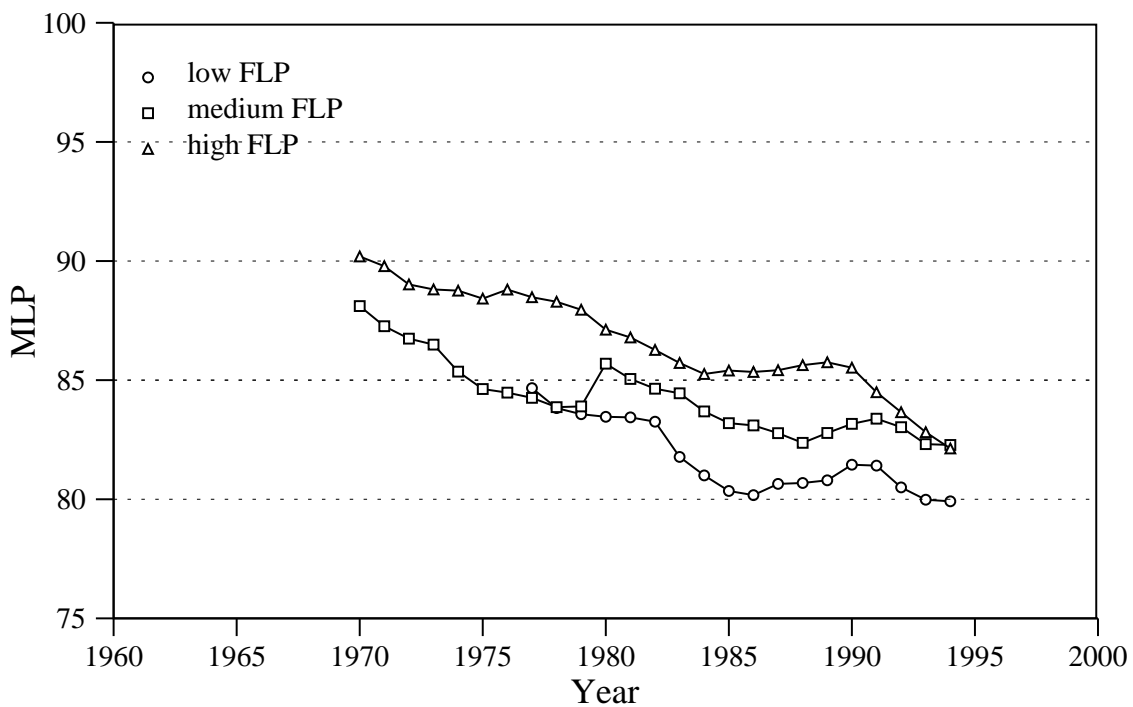

FA2, FA3). To compare the amount of allowances relative to male wages, FA1, FA2, and FA3 are divided by estimated monthly male wages. Since for most countries male wages were only available per hour, and weekly working hours were missing for most years and countries, we assumed an average of forty working hours per week and country. The estimation was then obtained by multiplying the hourly male wages by forty times four. ${ }^{4}$ All data on social policy indicators are taken from the preliminary Comparative Family Benefits Database 1970-2000 personally provided to us by A. Gauthier.

\section{Empirical Evidence}

We start our investigation by considering the change in the male economic position across time and space. While FLP has increased across time and space MLP shows a clear downward trend (Figure 5$)^{5}$ over the last three

\footnotetext{
${ }^{4}$ Sensitivity analysis yields that our results are robust to the assumption of constant working hours across time and countries.

${ }^{5}$ Since data on MLP are lacking for several countries prior to 1970 and after 1994 we present country averages only for 1970-1994. During this time period we are still missing
} 
Figure 6: Average male unemployment rates in low, medium and high participation countries

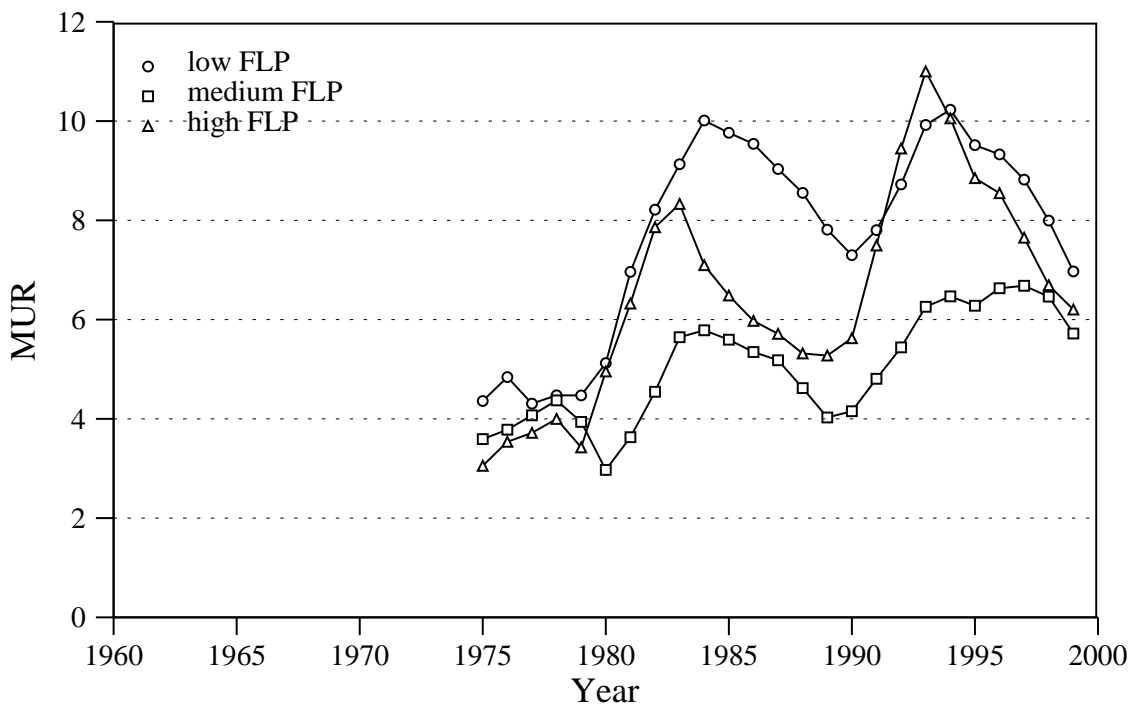

decades, which was particularly severe for the group of low FLP countries from 1982 to 1986, the time during which the cross-country relation between TFR and FLP changed its sign as well. In addition, the MUR in those countries with already low FLP and MLP rates increased the most during the time period 1980-1984 (Figure 6). ${ }^{6}$ These figures clearly evidence the fact that the male economic status became more unstable over time for all countries in our sample. This negative development was most pronounced for the group of countries with low FLP where the economic status of men might be of greater importance for fertility decisions and the negative income effect of a decline in MLP and an increase in MUR is most pronounced.

Not only was the male economic status the lowest in those countries with the lowest FLP, but the female unemployment rate was also the highest for those countries (Figure 7). ${ }^{7}$ The increase in the FUR in the low FLP countries

data for GRE, NET, POR and SPA. However the overall trend of MLP is independent of those missing values.

${ }^{6}$ Since data on MUR are lacking for several countries prior to 1974 we present country averages only for 1975-1999.

${ }^{7}$ Since data on FUR are lacking for several countries prior to 1974 we present country 
Figure 7: Average female unemployment rates in low, medium and high participation countries

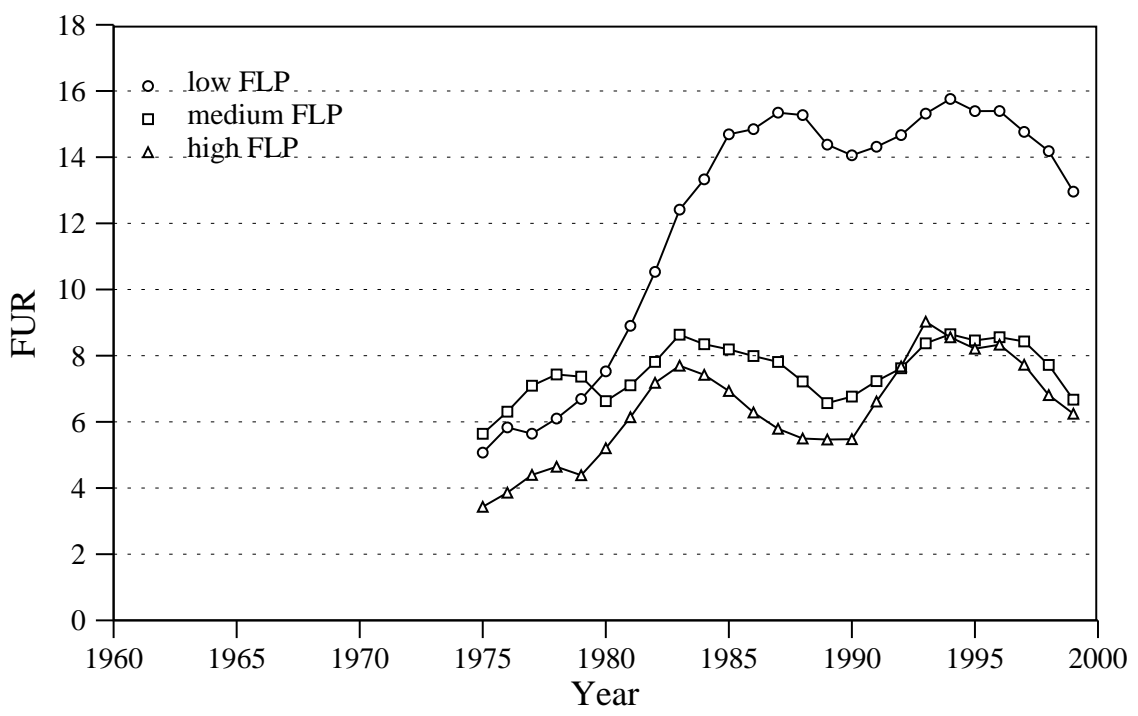

in the time period (1980-1985) coincides with the sharp decline in TFR in those countries. While the MUR and MLP show some convergence between low and high FLP countries or at least some stabilization during the 90s the FUR stays exceptionally high for those countries where FLP is the lowest and TFR decreased the most. It seems that the income effect dominated for those countries where FUR was highest and leads to the steep reduction in TFR. The fact that TFR declined the most in those countries with low FLP and high FUR may be further explained by the fact that those are also the countries where the economic status of males was the worst thereby reinforcing the negative income effect that resulted from the high level of FUR.

With the increase of FLP the gender wage gap declined over time (Figure 8). However, in the low FLP countries the gender wage gap stabilized between the early 80 s and the early 90s, the time period during which TFR declined strongly in those countries. Note that the ratio of female to male wages was lowest in the medium FLP countries. Hence, while the stagnating gender wage gap may have contributed to worsening females' role in the la-

averages only for 1975-1999. 
Figure 8: Gender wage-gap in low, medium and high participation countries

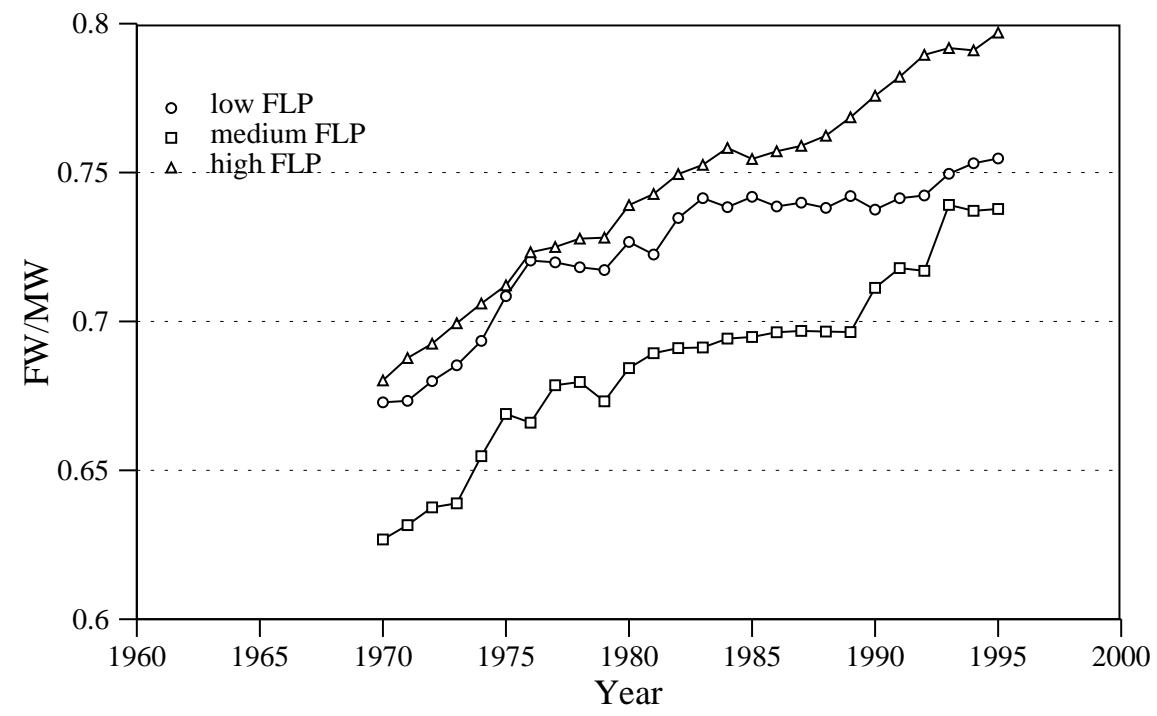

bor market in low FLP countries the gender wage gap was not exceptionally big in those countries. A comparison of the slope in the increase of male and female wages (Figure 9 and 10) shows that wages increased less steeply in low FLP countries as compared to high FLP countries.

Besides the labor market status of female and male partners, which determine the economic/income constraints on fertility, the flexibility in working hours may impinge on the compatibility of employment and childrearing. The possibility of part time work does not seem to be exceptionally low for our group of countries with low FLP (or conversely high in high FLP countries) (Table 3). ${ }^{8}$ For instance, the Netherlands is among the countries with low FLP during the $80 \mathrm{~s}$ and part of the $90 \mathrm{~s}$ but it has the highest share of part time employment for women in our sample of countries (most of the increase in FLP in the Netherlands is due to the increase in part time employment for women (Henkens, Grift and Siegers 2002)). On the contrary, FLP is among the highest in Finland but the share of women in part time

\footnotetext{
${ }^{8}$ Since data on part time employment are lacking for several time periods and countries we present the part time employment for each country and selected time points instead of presenting country averages for our three country groups. We use the the grouping suggested by Ahn and Mira as in Figure 3.
} 
Figure 9: Male wages in low, medium and high participation countries

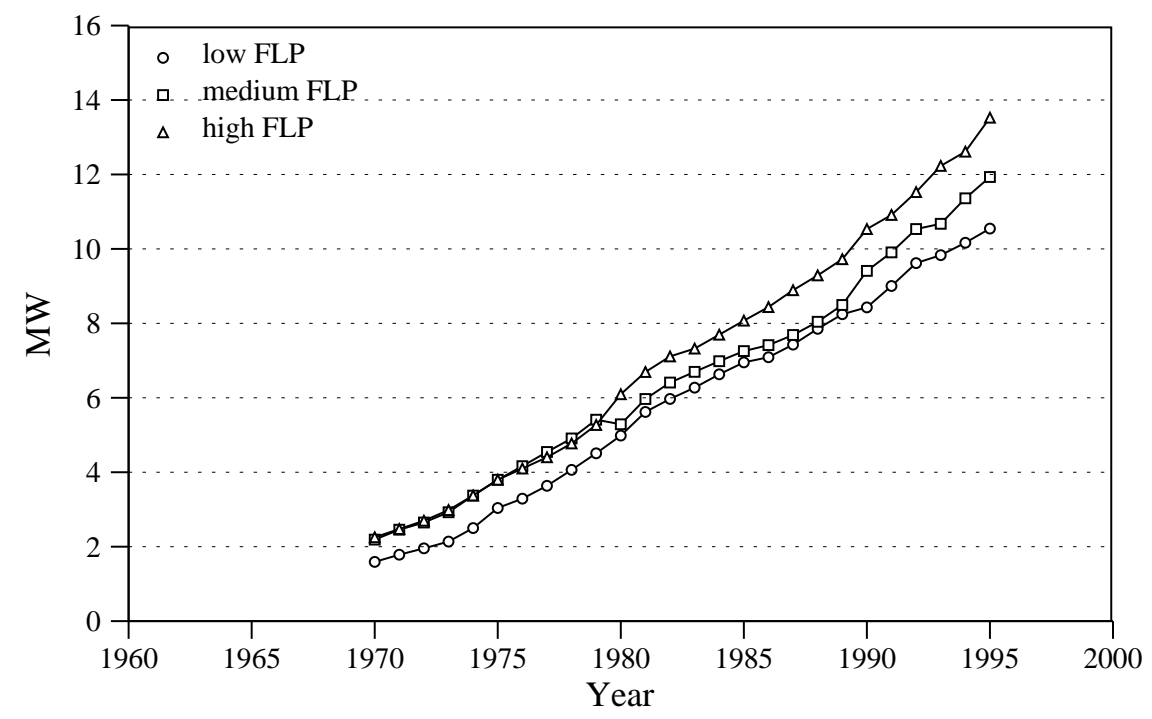

Figure 10: Female wages in low, medium and high participation countries

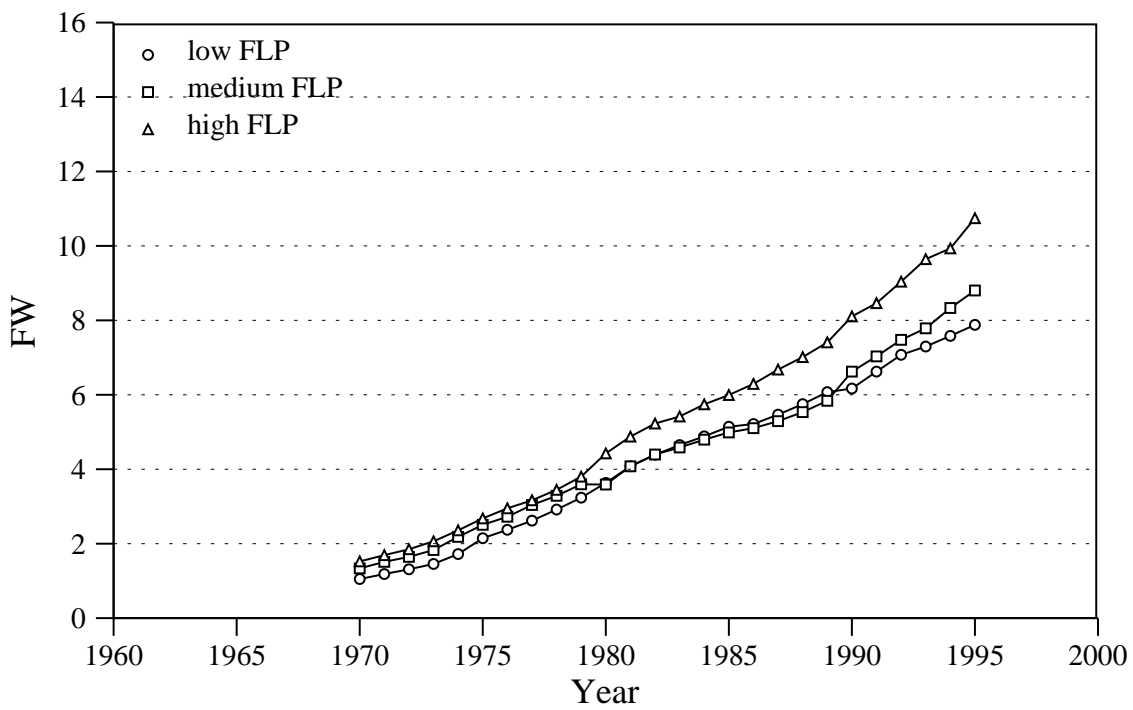


Table 3: Proportion of females employed part time in low, medium and high participation countries

\begin{tabular}{lllllll}
\hline \hline & & 1980 & 1985 & 1990 & 1995 & 2000 \\
\hline low participation & BEL & & 26.2 & 31.4 & 32.1 & \\
& GRE & & 10.8 & 11.5 & 13.2 & \\
& LUX & & 18.5 & 19.1 & 28.4 & 28.9 \\
& IRE & & 17.8 & 20.5 & 26.6 & 32.2 \\
& ITA & & 16 & 18.2 & 21.1 & 23.4 \\
& NET & & 45.5 & 52.5 & 54.7 & 57.2 \\
& SPA & & & 11.5 & 15.9 & 16.5 \\
medium participation & AUL & \multirow{2}{*}{34.9} & 36.9 & 38.5 & 40.2 & 40.7 \\
& AUS & & & & 21.6 & 24.4 \\
& FRA & & 20.3 & 21.7 & 24.3 & 24.3 \\
& FRG & & 25.4 & 29.8 & 29.1 & 33.9 \\
& JPN & 28.6 & 30 & 33.4 & 34.9 & 39.4 \\
& POR & & & 11.8 & 14.5 & 14.7 \\
high participation & CAN & 25.9 & 28.2 & 26.8 & 28.2 & 27.3 \\
& DEN & & 32.8 & 28.6 & 24.2 & \\
& FIN & \multirow{2}{*}{10.7} & 12.3 & 10.6 & 11.5 & 13.9 \\
& NOR & & & 39.8 & 37.5 & 33.6 \\
& SWE & & & 24.5 & 24.1 & 21.4 \\
& SWZ & & & & 44.9 & 44.7 \\
& UKM & & 41.1 & 39.5 & 40.7 & 40.8 \\
& USA & 21.9 & 21.5 & 20 & 20.3 & 18.2 \\
\hline
\end{tabular}

employment is the lowest. One should however keep in mind that comparing part time employment across countries might be flawed since its definition will vary across countries (OECD Labor Force Statistics 1980-2000). Most important for our argument is that the data underlying Table 3 do not show any exceptional slope in the change of part time employment for low FLP countries and may therefore not explain the exceptional drop in TFR in those countries during the 80 s.

Female hours worked is a further, and possibly less biased measure (since its definition is more clear-cut) that may explain the incompatibility between FLP and fertility. Table 4 gives some weak evidence that low FLP countries are less flexible in working hours for females. ${ }^{9}$ E.g. while the average FH is

\footnotetext{
${ }^{9}$ Similar to Table 3 data on female hours are lacking for several time periods and countries and we present female hours for each country and selected time points instead of
} 
Table 4: Female working hours per week in low, medium and high participation countries

\begin{tabular}{lllllll}
\hline \hline & & 1980 & 1985 & 1990 & 1995 & 2000 \\
\hline low participation & NET & 40.1 & 39.6 & 39.2 & 39 & \\
& GRE & 39.1 & 38.3 & 40.5 & 40 & 41 \\
& IRE & 36.9 & 37.6 & 37.9 & 36.3 & \\
& ITA & & & & 38.2 & 37.9 \\
& LUX & 38.4 & 39.4 & 38.4 & & \\
& SPA & 36.2 & 34.5 & 34.9 & 34.7 & 34 \\
medium participation & AUL & 33.8 & 32.7 & 33.2 & 32.9 & 33 \\
& AUS & & & & 32.8 & 33.2 \\
& FRG & 40 & 39.5 & 38.4 & & 37.4 \\
& JPN & 38.4 & 38.4 & & 34.7 & 34.5 \\
& POR & & 38.7 & 39.4 & & \\
high participation & FIN & & & & 36.2 & 36.2 \\
& NOR & 31.7 & 31.6 & 31.3 & 31.8 & 32.2 \\
& SWE & 32.8 & 33.5 & 34.5 & & \\
& UKM & 37.3 & 40 & 40.5 & 39.3 & 38.9 \\
\hline
\end{tabular}

around 40 for Greece, Swedish women work on average 7 hours less. How much the inflexibility in working hours has deterred women from entering the labor force in our group of low FLP countries cannot be determined by our aggregate descriptive illustrations. We may only conclude that in those countries with low FLP, the compatibility between labor force participation and childbearing is more difficult and may therefore have contributed to further depressing the TFR.

A further explanation of why fertility may have declined more rapidly in low FLP countries could be that educational variables have evolved differently in those countries for females. Figure 11 and 12 clearly refute such a hypothesis. Neither GER nor the average number of years of school for females has evolved differently in low FLP countries as compared to high and medium FLP countries. For all three country groups we observe an increasing trend for both variables over time with a higher level of female education in high FLP countries. We may only argue that as female education rises (for countries with both low and high FLP) the implication of high FUR and MUR and low MLP may change as well. For instance, the opportunity

presenting country averages for our three country groups. We use the grouping suggested by Ahn and Mira as in Figure 3. 
Figure 11: Tertiary gross enrolment ratio of females in low, medium and high participation countries

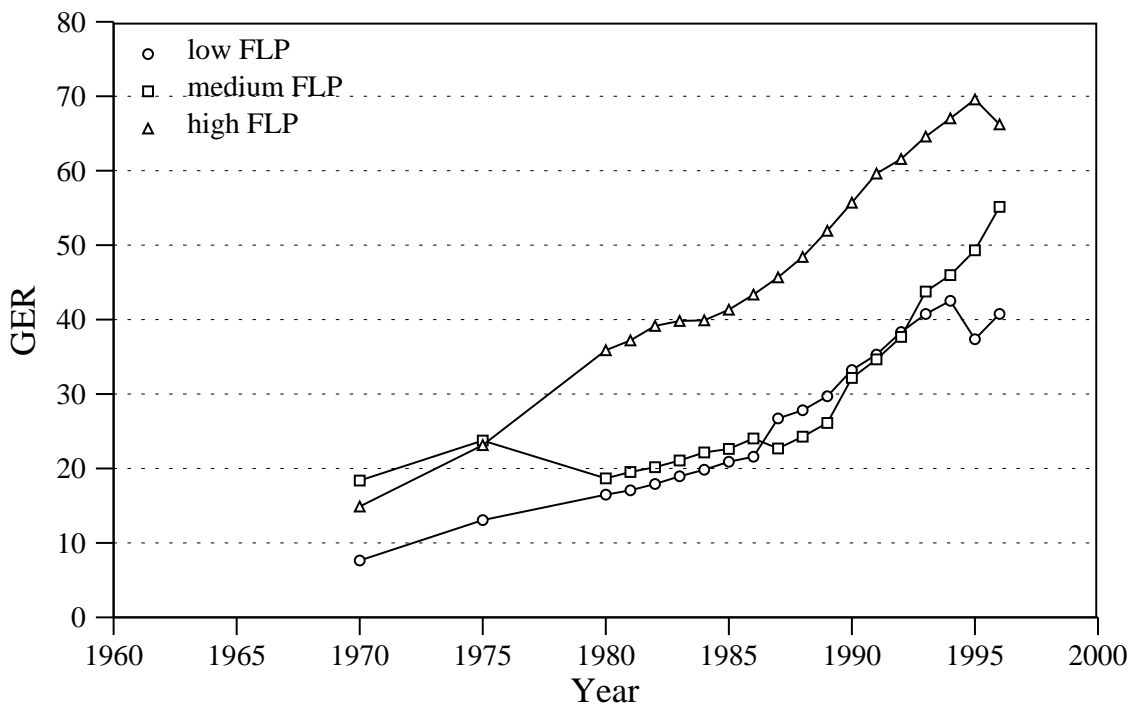

cost of being out of the labor force may increase with the number of years spent in education and an increase in FUR may therefore be more severely perceived and imply a more pronounced negative impact on fertility.

It is interesting to verify whether the decline in fertility has been accompanied by an equally pronounced decline in any of the proximate determinants of fertility behavior. While total female first marriage rates (TFFMR) were stable for low FLP countries and declining for high and medium FLP countries up to the early 1970s, TFFMR have declined thereafter for all three country groups (Figure 13). We observe a convergence of TFFMR among the three country groups since the early $80 \mathrm{~s}$. From a time series point of view we may argue that marriage is still a valid proximate determinant of fertility behavior since the overall decline in TFR was accompanied by a decline in TFFMR. However, from a cross sectional view the marriage rate is no longer positively correlated to fertility, as is also shown in Billari and Kohler for European lowest low fertility countries (2002) and in Figure 13. TFFMR and TFR may still be closely interdependent in countries where long-term commitment to partnership is still the norm. In these countries (e.g. Italy) any decrease in TFFMR (caused for instance by the declining economic sta- 
Figure 12: Average years of schooling of females in low, medium and high participation countries

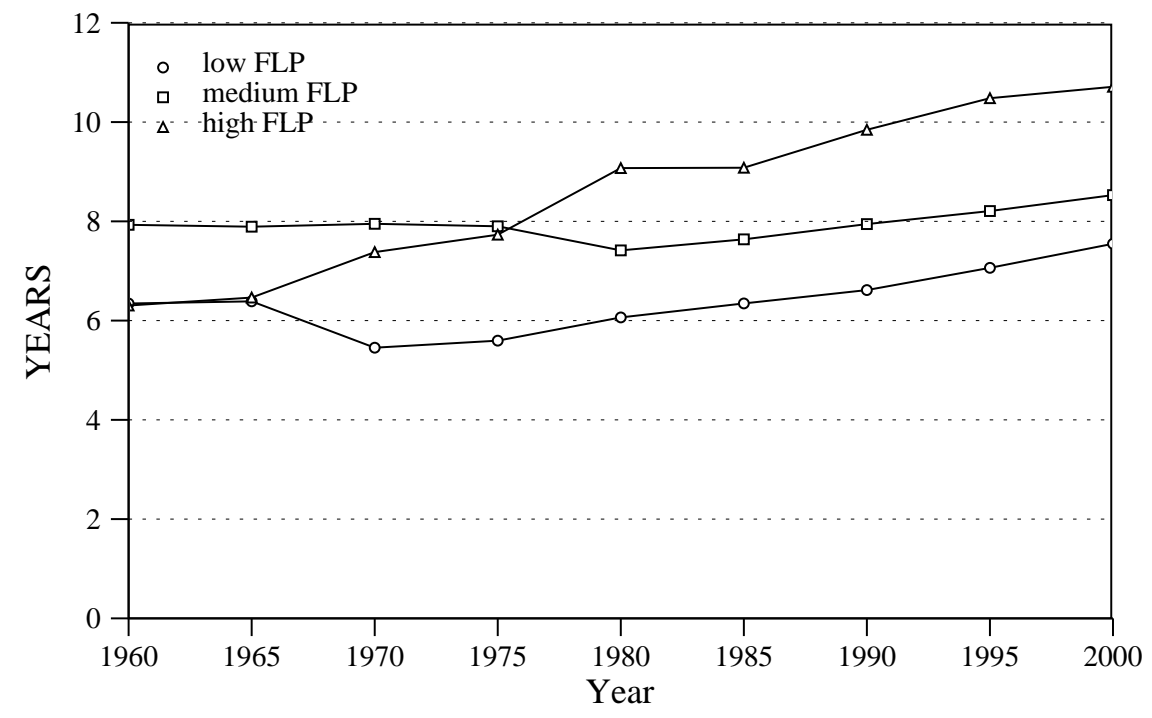

tus of men and women) may therefore be linked to the pronounced decrease in TFR.

A further proximate determinant of fertility behavior may be the total divorce rate. Figure 14 rejects the hypothesis that an exceptionally high divorce rate among low FLP countries may be a driving factor for the pronounced decrease in the fertility in those countries. TDR is lowest for low FLP countries over the whole time period considered.

Besides partnership formation and dissolution the age at first birth belongs to the group of proximate determinants of fertility behavior. Age at first birth is of particular interest with respect to the postponement of childbearing, which has been cited as one of the systematic patterns of lowest low fertility (cf. Billari and Kohler 2002). Figure 15 indicates that the drop in fertility in low FLP countries may be related to their more pronounced increase in MAB1. ${ }^{10}$ While MAB1 was lowest among low FLP countries during the $70 \mathrm{~s}$ and started to increase with a lag of about 5 years compared to the high FLP countries, MAB1 is now highest among low FLP countries.

\footnotetext{
${ }^{10}$ We do not have data on MAB1 for AUL, CAN, JPN, most of the time periods in LUX, nor on early time periods for Norway and Spain.
} 
Figure 13: Total female first marriage rate in low, medium and high participation countries

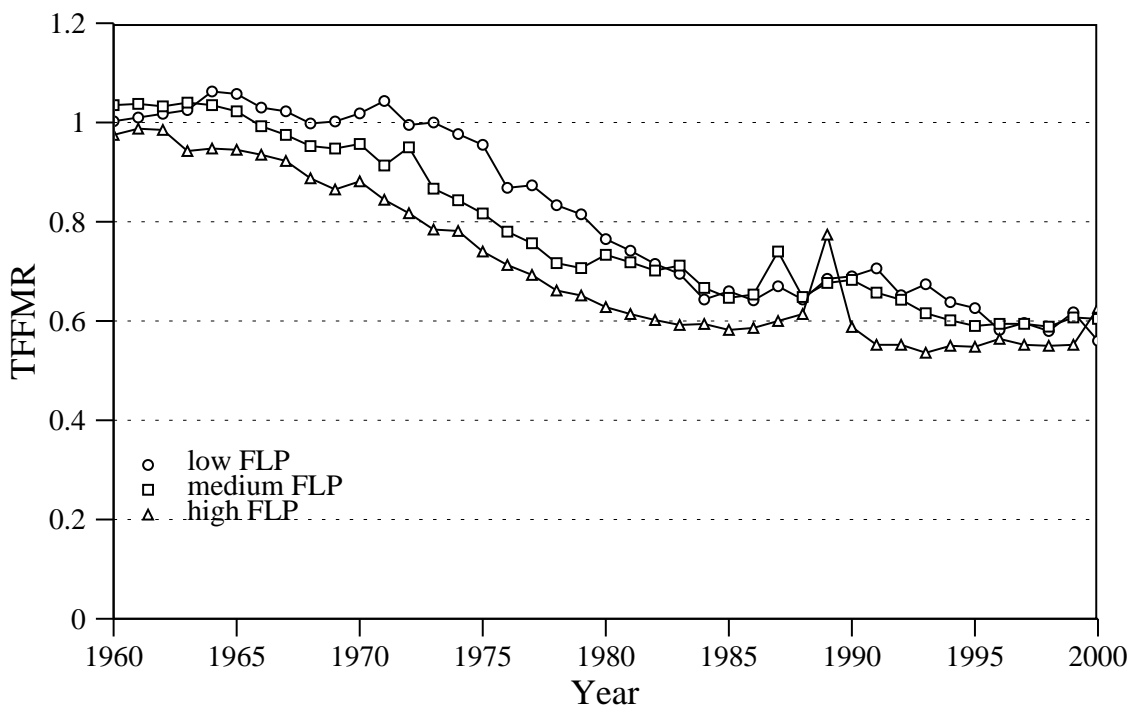

Figure 14: Total divorce rate in low, medium and high participation countries

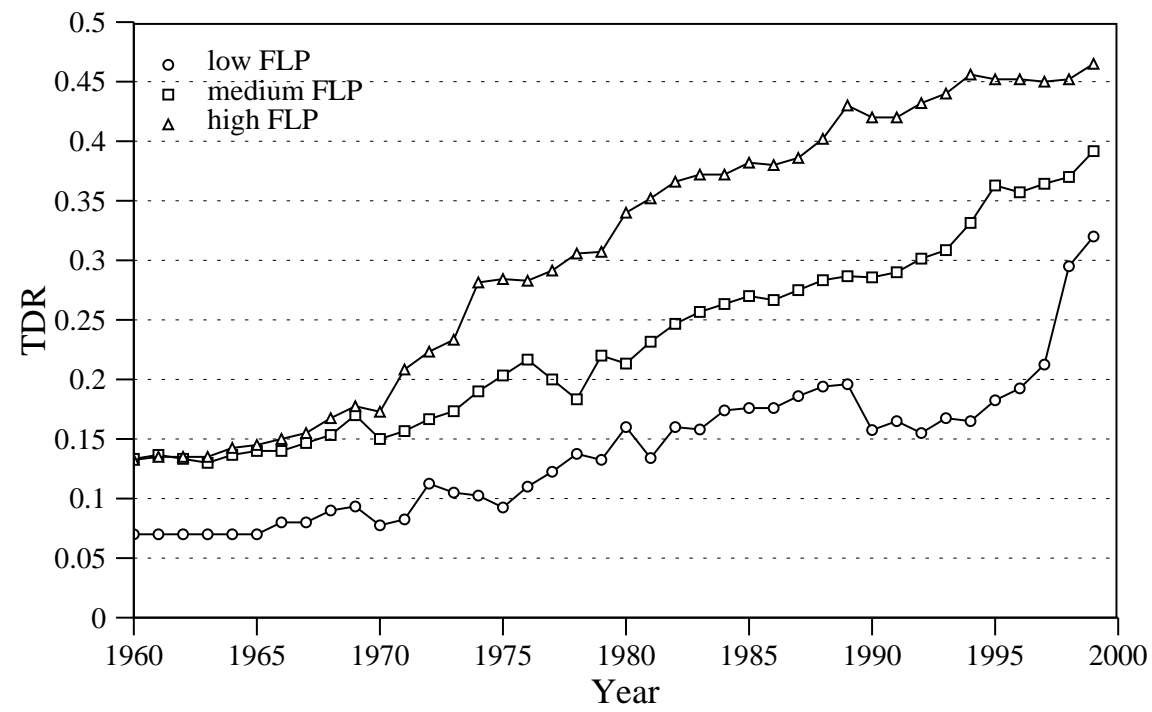


Figure 15: Mean age at first birth in low, medium and high participation countries

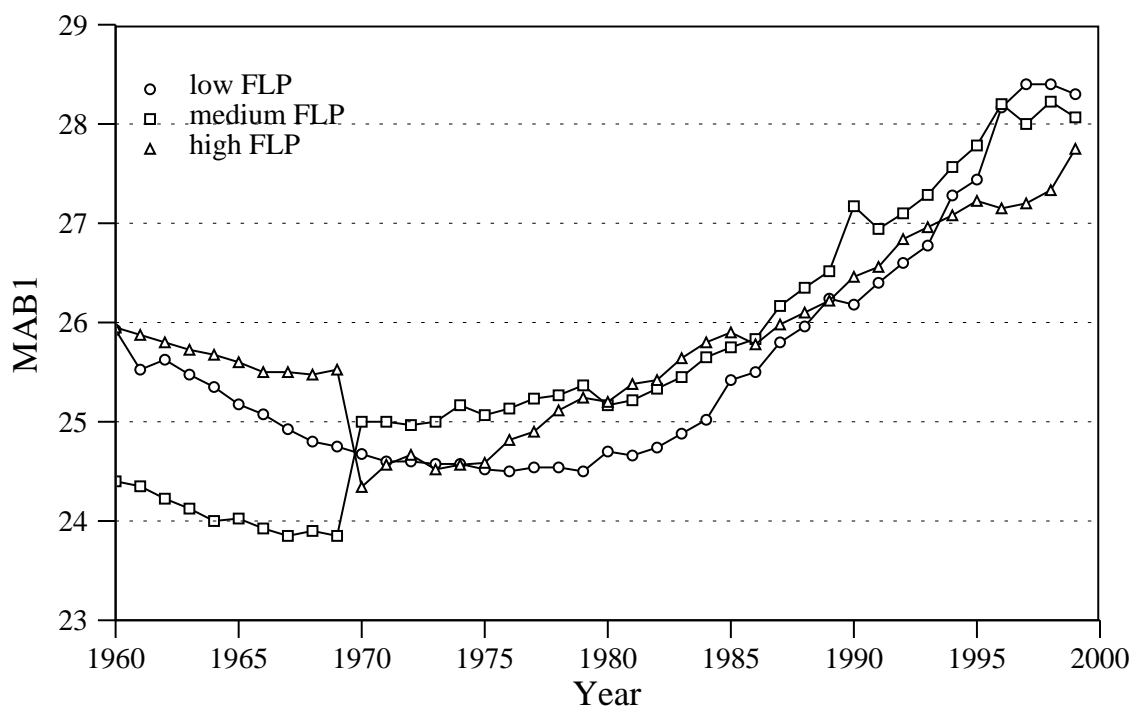

Though a delay in childbearing does not necessarily correlate with a low TFR (e.g. the Netherlands have one of the highest MAB1 but their TFR is among the highest while for Greece MAB1 is among the lowest while TFR in Greece has dropped markedly in the 80s and 90s), an increase in MAB1 has lowered the progression probability after the first child at least for part of the low FLP countries included in our study (cf. Billari and Kohler 2002).

From the previous discussion we may conclude that TFFMR, TDR and MAB1 may still be proximate determinants of fertility behavior from a time series point of view (we observe a decline in TFR that goes hand in hand with a decrease in TFFMR and an increase in TDR and MAB1). However, the cross-country relationship between partnership formation and dissolution and fertility as well as between the age at first childbearing and fertility has become indeterminate during the late 90s (cf. Billari and Kohler 2002). Nevertheless, our illustrations indicate that for low FLP countries the drop in TFFMR and the increase in MAB1 was more pronounced during the time period when TFR dropped the most. We regard these findings as evidence that the less fortunate economic conditions in those countries may have had a profound impact on these proximate determinants of fertility and therefore 
reinforced the direct negative impact of economic conditions on fertility.

We conclude our descriptive representations with the consideration of social policy variables. Figure 16 plots the gross enrolment ratio of children in pre-primary education (PREM). ${ }^{11}$ Surprisingly, PREM was highest among low FLP countries and lowest for high FLP countries since the late 70s. We are cautious to interpret these findings as evidence for the higher compatibility of child rearing and labor force participation in low FLP countries since a well established literature (on the micro as well as macro level) exists, showing that family policies and social norms are lacking in many of the countries where we observe the lowest levels of fertility in the 80s and 90s (Gornick et al. 1997). More likely these results may be evidence for the fact that a higher gross enrolment ratio of children in pre-primary education is not contributing significantly to lowering child-care costs and time costs of raising and educating a child. One explanation may be that in those countries where PREM is low there are other childcare systems available for children at pre-primary education age. As previous studies have shown, the availability of childcare at younger ages may have a higher variance across countries (OECD 2001).

Further indicators that may reduce the incompatibility of childrearing and labor force participation by reducing the opportunity costs of children are family allowances. We calculate the share of FA as a percentage of the monthly male wage income to compare the importance of FA across countries and present only family allowance for first children (FA1) where differences across countries are most pronounced. Figure 17 indicates that FA1 are lowest for low FLP countries and, even more importantly, FA1 declined during the mid 80s for low FLP countries, the time period when TFR dropped the most in those countries. ${ }^{12}$ During the early 90 s, FA1 increased considerably in high FLP countries while the increase was more moderate in low FLP countries (apart from the increase at the beginning of the 90s which is mainly due to the increase in FA1 in Spain at this time). We may conclude that the higher share of FA1 in high FLP countries may have had a positive impact on fertility by reducing the opportunity costs of childbearing while the lower level of FA1 in low FLP countries may have further depressed fertility since opportunity costs are higher.

\footnotetext{
${ }^{11}$ We are missing data for PREM for the time period before 1970. Data are also incomplete for several countries. However, the general picture in Figure 16 is not perturbed by these omissions.

${ }^{12}$ Data on FA1 are missing for several time periods and for the USA and FRA. The high levels of FA1 for the medium FLP countries is mainly driven by the high FA1 in Austria.
} 
Figure 16: Gross enrolment ratio in pre-primary education in low, medium and high participation countries

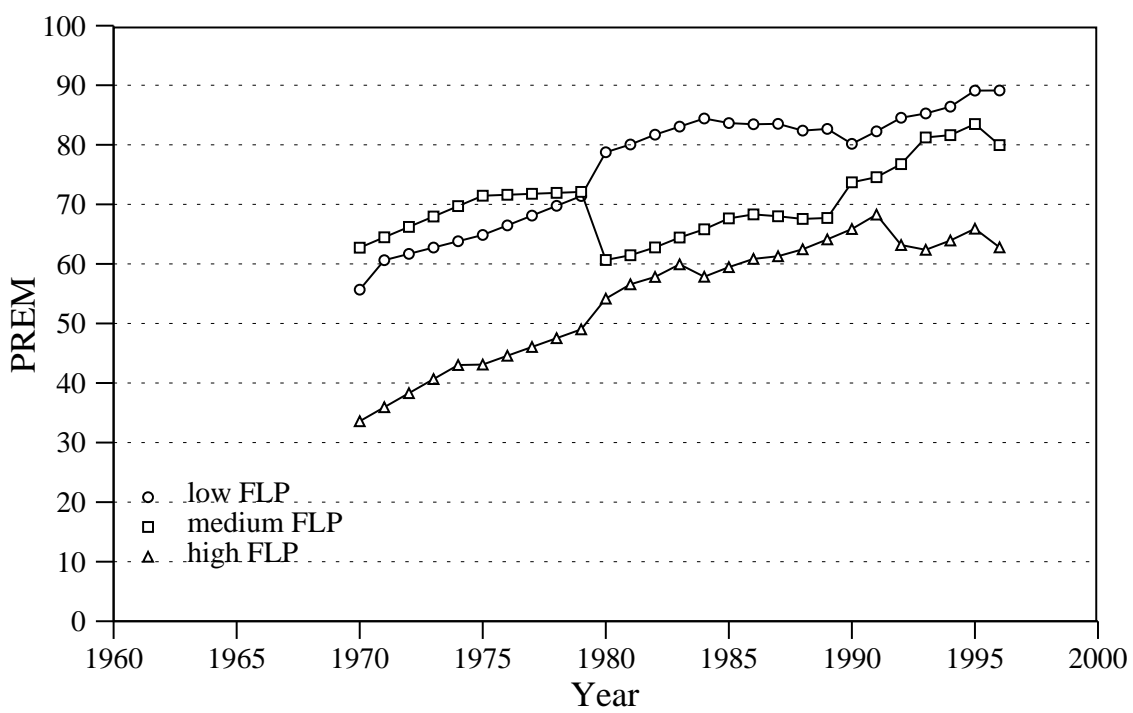

Figure 17: Share of family allowances for first child on the monthly male wage income in low, medium and high participation countries

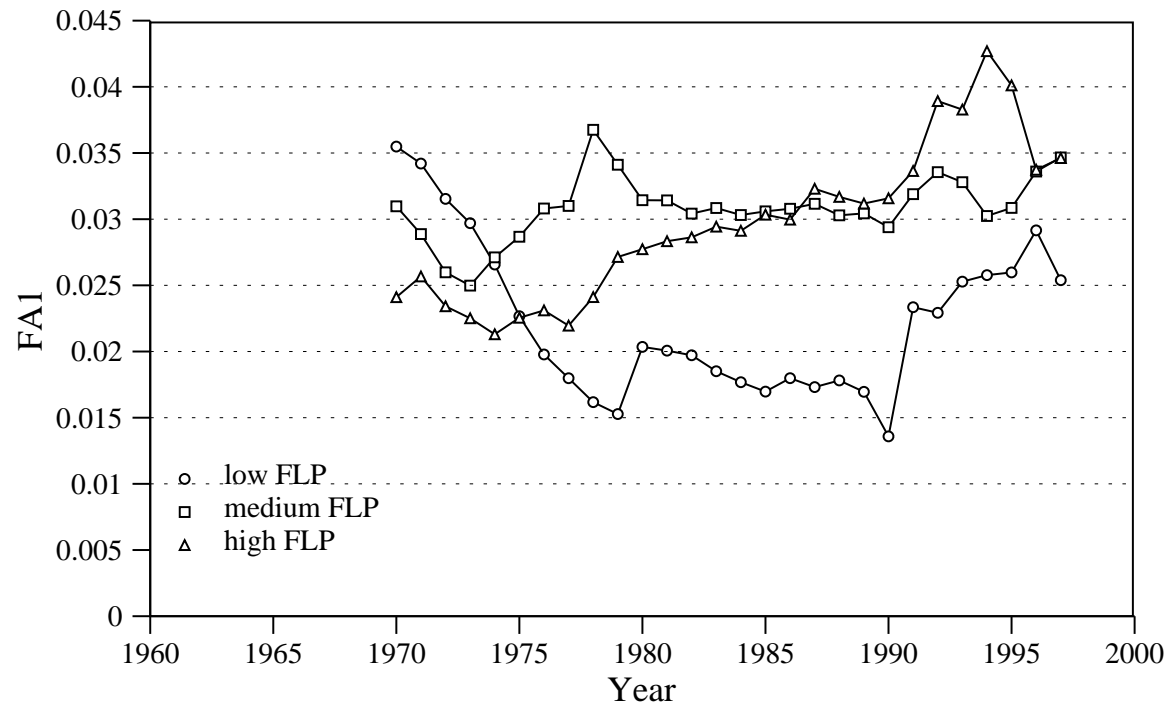




\section{Discussion}

According to a recent piece of literature, unmeasured country-specific factors as well as country-heterogeneity in the magnitude of the negative time-series association accounts for the change in the cross-country correlation between the total fertility rate and the female labor market participation rate (Kögel 2002). In this study we have tried to identify the factors that may explain country heterogeneity in the negative association between fertility and female employment.

Our methodological approach is purely descriptive due to severe data restrictions of the available macro data. To account for country-heterogeneity we start off by building country groups that are homogeneous with respect to the development of their female participation rates. This grouping is done in a dynamic way that accounts for country-specific heterogeneity in the increase in female employment. Different slopes for various indicators over time help us to understand the changing mediating relationship between these factors and the fertility/employment nexus. The methodological approach is interpretative, though mainly guided by family economic and role incompatibility considerations. Due to data limitations we were not able to explicitly test Easterlin's relative income hypothesis.

The family economic approach focuses primarily on changes in the value of women's time as the driving force between changes in fertility and female employment. Since women's time is affected by numerous factors with a certain variety in time and space, this approach seems to be a reasonable starting point for our considerations. The empirical analyses are supplemented by implications of the role incompatibility approach according to which societal level responses have eased the incompatibility between childrearing and female employment. This alternative approach focuses less narrowly on the female wage as a measure of the price of women's time, and instead turns attention to the ability of women to combine childbirth and work.

In our empirical analysis, we consider labor market variables, educational variables and demographic variables as well as indicators of social policy. Regarding the theoretically suggested labor market indicators, our results indicate that male labor force participation and male unemployment rates became more unstable over time and that this development was most pronounced in low female employment countries. The increase of female unemployment in the beginning of the 80s in low participation countries coincides with the sharp decline in fertility. Female and male wages increased over 
time for all countries included in our study with a slightly lesser slope in low FLP countries as compared to high FLP countries. However in low participation countries the female to male wage ratio stagnated during the $80 \mathrm{~s}$ as compared to the continuous improvement in high participation countries. Surprisingly, the share of part time employment for women does not correlate with the participation rate and the only slight increase in most countries may not explain the drop in fertility. However, there seems to be less flexibility in working hours in low than in high participation countries.

Considering education, neither the tertiary gross enrolment ratio nor the average years of schooling of females has evolved differently in countries with low female labor force participation. We may only assert that as female education has risen the implication of opportunity costs (e.g., due to female and male unemployment) may have changed as well.

In all countries included in our study the decline in fertility was accompanied by a general decline in female first marriage rates and an increase in total divorce rates. However, we do not observe any difference in the change of these demographic variables between countries of low and high female labor force participation. We find evidence that the drop in fertility in countries with low female labor force participation is related to the postponement of a first child.

Concerning our indicators for social policy we do not find support that an increase in the gross enrolment ratio of kids in pre-primary education accounts for the change in cross-country correlation. However, we find some evidence that the share of family allowances for the first child as a percentage of the monthly male wage income are lowest for countries with low female labor force participation, and they have declined during the time period when fertility dropped most in those countries.

From a family's economic point of view, our results suggest that the negative income effect of a decline in male labor participation rates and an increase in male unemployment rates is most pronounced in the group of countries with low FLP. Furthermore, it seems that the income effect dominated for those countries where the female unemployment rate was highest. The negative income effect resulting from a high level of female unemployment in those countries with low FLP was most likely reinforced by the worse economic status of males. The higher share of family allowances in high female participation countries may have had a positive impact on fertility by reducing the opportunity costs of childbearing and rearing. In sum, male labor participation, male and female unemployment and the share of family 
allowances for the first child may be responsible for the country heterogeneity in the magnitude of the negative time-series association between fertility and female employment.

The changing correlation between TFR and FLP can also be understood from the emerging alternative role incompatibility hypothesis in the demographic literature. We have some weak evidence that low FLP countries are less flexible in working hours for females. Here, the compatibility between labor force participation and childbearing is more difficult and may therefore have contributed to further depressing the TFR. The change in the gross enrolment ratio of children in pre-primary education, however, does not seem to reduce the work-children incompatibility in low participation countries. This result suggests that child-care costs and the time costs of raising and educating a child do not seem to be considerably lowered by the existing forms of pre-primary education in low employment countries. However, our measures of child care (PREM) and direct payments for children (FA1) do not completely capture the true story. Recently, Apps and Rees (2001: 15) conclude from a formal analysis that "this result tells us that in two otherwise identical economies, the one which places more weight on subsidising bought-in child care and less on direct child payment will have both higher fertility and higher female labor supply."

Our results also indicate that on a cross-country level, demographic indicators such as the TFFMR or the TDR are no longer valid proximate determinants of fertility. In line with the argument given by Billari and Kohler (2002), long term partnership commitments in many of the low FLP countries included in our study may have been an obstacle rather than a fortune for fertility. As TFFMR and TDR decreased and respectively increased in low FLP countries, fertility levels dropped faster as compared to high FLP countries where long term commitments of partnerships and childbearing are less connected (Prskawetz et al. 2002). One may argue that the decline in TFFMR and the increase in TDR in high FLP countries was independent of the economic status of male and females and more a sign of liberal partnerships. In low FLP countries, the drop in TFFMR and TDR was closely connected to the worsening economic status of males and most likely not a sign of more liberal partnerships. Moreover, as discussed in Bettio and Villa (1998) a 'cohesive family has encouraged very low fertility' in the Mediterranean low FLP countries.

The descriptive evidence on the cross-national patterns do not, of course, prove that the change in the cross-country correlation between fertility and 
female employment is due to country-specific changes in income structures and societal level circumstances in combining fertility and female employment. More evidence would be needed in order to build a strong case for such a relationship. However, many Asian countries with a traditional conservative family pattern and increasing female employment rates could provide a test for such a relationship. According to our descriptive findings for OECD countries we would expect a decrease in fertility in the near future.

A clear message of our aggregate descriptive representations is that female labor force participation represents only one dimension in a set of indicators that determines cross-country differences in the economics of the family. To understand cross-country differentials in fertility it is necessary to consider a broader spectrum of confounding indicators such as those related to male and female economic status, institutional arrangements and the role of proximate determinants of fertility across countries. 


\section{References}

Ahn Namkee and Pedro Mira. 2002. "A Note on the Changing Relationship between Fertility and Female Employment Rates in Developed Countries," Journal of Population Economics 15(4)4: 667-682.

Andersson, Gunnar. 2001. "The impact of labour-force participation on childbearing behavior: pro-cyclical fertility in Sweden during the 1980s and the 1990s," European Journal of Population 16: 293-333.

Apps, Patricia and Ray Rees. 2001. "Fertility, Female Labor Supply and Public Policy," Discussion Paper No. 409, Institute of the Study of Labor (IZA), Bonn, Germany.

Barro, Robert J. and Jong-Wha Lee. 2001. "International data on educational attainment: updates and implications," Oxford Economic Papers 3: 541-563.

Becker, Gary S. 1991. A Treatise on the Family, enl. ed. Cambridge, Mass.: Harvard University Press.

Benjamin, Karen. 2001. "Men, Women, and Low Fertility: Analysis Across Time and Country," Unpublished Working Paper, Chapel Hill: University of North Carolina.

Bettio, Francesca and Paola Villa. 1998. "A Mediterranean Perspective on the BreakDown of the Relationship Between Participation and Fertility," Cambridge Journal of Economics 22: 137-171.

Billari, Franceso and Hans-Peter Kohler. 2002. "Patterns of Lowest-Low Fertility in Europe," MPIDR Working Paper WP 2002-040, Rostock: Max Planck Institute for Demographic Research.

Brewster, Karin L. and Ronald R. Rindfuss. 2000. "Fertility and Women's Employment in Industrialized Nations," Annual Review of Sociology 26: 271-296.

Butz, William P. and Michael P. Ward. 1979. "The Emergence of Countercyclical U.S. Fertility," American Economic Review 69: 318-328.

Council of Europe. 2001. Recent Demographic Developments in Europe. Strasbourg: Council of Europe Publishing.

Cherlin, Andrew. 1992. Marriage, Divorce, Remarriage. Cambridge, Mass.: Harvard University Press.

Cigno, Alessandro. 1991. Economics of the Family. Oxford: Clarendon Press.

de la Fuente, Angel and Rafael Doménech. 2002. "Educational Attainment in the OECD, 1960-1995," Unpublished manuscript. 
DiPrete, Thomas A., S. Philip Morgan, Henriette Engelhardt, and Hana Pacalova. 2002. "Do Cross-National Differences in the Costs of Children Influence Fertility Behavior?" Unpublished manuscript.

Easterlin, Richard A. 1978. "What will 1984 be like?" Demography 15: 397-421.

Easterlin, Richard A. 1980. Birth and Fortune: The Impact of Numbers on Personal Welfare. New York: Basic Books.

Easterlin, Richard A. 1987. "Easterlin Hypothesis," in J. Eatwell, M. Milgate, and P. Newman (eds.), The New Palgrave: A Dictionary to Economics 2, pp. 1-4. New York: The Stockton Press.

Engelhardt, Henriette, Tomas Kögel, and Alexia Prskawetz. 2001. "Fertility and female employment reconsidered: A macro-level time series analysis," MPIDR Working Paper WP 2001-021, Rostock: Max Planck Institute for Demographic Research.

Ermisch, John. 1979. "The Relevance of the 'Easterlin Hypothesis' and the 'New Home Economics' to Fertility Movements in Great Britain," Population Studies 33: 39-58.

Esping-Andersen, Gsta. 1999. Social Foundations of Postindustrial Economies. Oxford: Oxford University Press.

Galor, Oded and David N. Weil. 1996. "The Gender Gap, Fertility and Growth," American Economic Review 86: 374-387.

Gauthier, Anne H. 1996. The State and the Family: A Comparative Analysis of Family Policies in Industrialized Countries. Oxford: Clarendon Press.

Gauthier, Anne H. and Jan Hatzius. 1997. "Family Benefits and Fertility: An Econometric Analysis," Population Studies 51: 295306.

Gauthier, Anne H. 2002. "Comparative Family Benefits Database 1970-2000," unpublished database.

Gornick, Janet C., Marcia K. Meyers, and Kathrin E. Ross. 1997. "Supporting the Employment of Mothers: Policy Variation Across Fourteen States," Journal of European Social Policy 7: 45-70.

Heckman, James J. and James R. Walker. 1990. "The Relationship between Wages and Income and the Timing and Spacing of Births: Evidence from Swedish Longitudinal Data," Econometrica 58: 1411-1441.

Henkens, Kène, Yolanda Grift, and Jacques Siegers. 2002. "Changes in female labor supply in the Netherlands 1989-1998: The case of married and cohabiting women," European Journal of Population 18: 39-57. 
Hotz, V. Joseph, Jacob A. Klerman, and Robert J. Willis. 1997. "The Economics of Fertility in Developed Countries," in M. R. Rosenzweig and O. Stark (eds.), Handbook of Population and Family Economics, pp. 275-347. Amsterdam: Elsevier.

Huber, Evelyne, Charles Ragin, and John D. Stephens. 1997. "Comparative Welfare Data Set," online available: http://lisweb.ceps.lu/publications/welfaredata/welfareaccess.htm.

Kögel, Tomas. 2002. "Did the Association between Fertility and Female Employment Within OECD Countries Really Change its Sign?" MPIDR Working Paper WP 2001/034, Rostock: Max Planck Institute for Demographic Research.

Kravdal, Øystein. 2002. "The Impact of Individual and Aggregate Unemployment and Fertility in Norway," Demographic Research, Vol. 6, Article 10. Online www.demographicresearch.org.

Macunovich, Diane A. 1996. "A Review of Recent Developments in the Economics of Fertility," in P. Menchik (ed.), Household and Family Economics, pp. 91-150. Kluwer: Academic Press.

Macunovich, Diane A. 1998. "Fertility and the Easterlin Hypothesis: An Assessment of the Literature," Journal of Population Economics 11: 53-111.

OECD. 2002. OECD Labor Force Statistics 1980-2000. Paris: Organization for Economic Cooperation and Development.

OECD. 2001. Employment Outlook. Paris: Organization for Economic Cooperation and Development.

O'Reilly, Jacqueline and Colette Fagan, eds. 1998. Part-time Prospects. An International Comparison of Part-time Work in Europe, North America and the Pacific Rim. London, New York: Routledge.

Pampel, Fred C. and H. Elisabeth Peters. 1995. "The Easterlin Effect," Annual Review of Sociology 21: 163-194.

Prskawetz, Alexia, Andres Vikat, Dimiter Philipov, and Henriette Engelhardt. 2002. "Pathways to Stepfamily Formation in Europe: Results from the FFS," MPIDR Working Paper WP 2002-046, Rostock: Max Planck Institute for Demographic Research.

Rindfuss, Ronald R. and Karin L. Brewster. 1996. "Childrearing and Fertility," Population and Development Review 22 (Supplement): 258-289.

Rindfuss, Ronald R., Karen Benjamin, and S. Philip Morgan. 2000. "The Changing Institutional Context of Low Fertility," working paper, University of North Carolina.

Sanderson, Warren C. 1976. "On Two Schools of Economics of Fertility," Population and Development Review 2: 469-477. 
Willis, Robert J. 1973. "A New Approach to the Economic Theory of Fertility Behavior," Journal of Political Economy 81: S14-S64. 


\section{Appendix A}

Ahn and Mira (2002)

Grouping of countries by FLP over the time period 1970-1996:

\begin{tabular}{ccc}
\hline \hline High FLP $(>60 \%)$ & Medium FLP $(50 \%<<60 \%)$ & Low FLP $(<50 \%)$ \\
\hline FIN & AUS & GRE \\
SWE & FRA & IRE \\
DEN & FRG & ITA \\
UKM & AUL & SPA \\
USA & JPN & NET \\
NOR & POR & BEL \\
CAN & NZL & \\
SWZ & & \\
\hline
\end{tabular}

\section{Our grouping}

Grouping of countries by FLP over the time periods 1960-1969, 1970-1979, 1980-1989, 1990-1999. In addition to Ahn and Mira (2002) we also include Luxembourg while we exclude New Zealand due to different data sources on which the FLP series is based before 1985 and after 1985.

1960-1969:

\begin{tabular}{ccc}
\hline \hline High FLP $(>50 \%)$ & Medium FLP $(40 \%<<50 \%)$ & Low FLP $(<40 \%)$ \\
\hline FIN & DEN & IRE \\
JPN & FRA & ITA \\
SWE & FRG & LUX \\
SWZ & UKM & NET \\
AUS & USA & BEL \\
& AUL & CAN \\
\hline
\end{tabular}

Note: we exclude Norway from this time period since the FLP has been obtained from two different data sources before and after 1970. Data for Greece, Spain and Portugal are not available for this time period. 
1970-1979:

\begin{tabular}{ccc}
\hline \hline High FLP $(>50 \%)$ & Medium FLP $(40 \%<<50 \%)$ & Low FLP $(<40 \%)$ \\
\hline FIN & AUS & GRE \\
JPN & FRG & IRE \\
SWE & AUL & ITA \\
SWZ & BEL & LUX \\
DEN & CAN & NET \\
FRA & & SPA \\
UKM & & \\
USA & & \\
NOR & &
\end{tabular}

Note: Data for Portugal are not available for this period.

1980-1989:

\begin{tabular}{ccc}
\hline \hline High FLP $(>60 \%)$ & Medium FLP $(45 \%<<60 \%)$ & Low FLP $(<45 \%)$ \\
\hline FIN & AUS & GRE \\
SWE & FRA & IRE \\
DEN & FRG & ITA \\
UKM & AUL & LUX \\
USA & BEL & NET \\
NOR & JPN & SPA \\
CAN & POR & \\
& SWZ
\end{tabular}

1990-1999:

\begin{tabular}{ccc}
\hline \hline High FLP $(>65 \%)$ & Medium FLP $(50 \%<<65 \%)$ & Low FLP $(<50 \%)$ \\
\hline FIN & AUS & GRE \\
SWE & FRA & IRE \\
DEN & FRG & ITA \\
UKM & AUL & LUX \\
USA & BEL \\
NOR & JPN & \\
CAN & POR & \\
& SWZ & \\
& NET & \\
\hline
\end{tabular}

